\title{
Copenhagen City Heart Study: Iongitudinal analysis of ventilatory capacity in diabetic and nondiabetic adults
}

\author{
P. Lange*,\#, J. Parner*, ${ }^{*}$ P. Schnohr*, G. Jensen*
}

Copenhagen City Heart Study: longitudinal analysis of ventilatory capacity in diabetic and nondiabetic adults. P. Lange, J. Parner, P. Schnohr, G. Jensen. (C) ERS Journals Ltd 2002.

ABSTRACT: The natural history of lung function in diabetes is unknown due to the lack of longitudinal observations.

The decline of forced expiratory volume in one second (FEV1) and forced vital capacity (FVC) was studied over $15 \mathrm{yrs}$ in the 17,506 adult participants of The Copenhagen City Heart Study, which included 266 individuals with diabetes.

Multiple linear regression and a mixed-effects model were used, taking into account correlation between repeated measurements and adjusting for relevant confounders. In both sexes, FEV1 and FVC were consistently lower in diabetic individuals, compared with healthy individuals, with an average reduction of $\sim 8 \%$ of the predicted value. Longitudinal analyses showed that the decline of FEV1 and FVC in diabetic individuals was similar to that observed in nondiabetic subjects.

It was concluded that although diabetic subjects have, on average, a lower forced expiratory volume in one second and forced vital capacity than individuals without diabetes, this deficit seems not to be progressive in the long term. These observations may be of importance with regard to diabetes treatment with inhaled pulmonary insulin, which is likely to become available within a few years.

Eur Respir J 2002; 20: 1406-1412.

\author{
*Copenhagen City Heart Study, \\ Bispebjerg University Hospital, \\ Copenhagen, ${ }^{\#}$ Dept of Respiratory \\ Medicine, Hvidovre University Hospi- \\ tal, Hvidovre, and "Dept of Biostatis- \\ tics, University of Copenhagen, Panum \\ Institute, Copenhagen, Denmark.
}

Correspondence: P. Lange, Dept of Respiratory Medicine 223, Hvidovre University Hospital, DK-2650 Hvidovre, Denmark.

Fax: 4536323784

E-mail: peter.lange@hh.hosp.dk

Keywords: Diabetes mellitus, longitudinal study, lung function

Received: June 122002

Accepted after revision: July 222002

The Copenhagen City Heart Study was supported by grants from The Danish Heart Foundation and The Danish Medical Research Council. The analysis of lung function decline in diabetes was supported financially by Pfizer.
Numerous studies of lung function in diabetic subjects have shown slightly decreased indices of forced expiration, lung volumes and diffusion capacity in both type-1 [1-17] and type-2 diabetes [18-24]. Almost all of these studies are cross-sectional and include a small number of patients.

Both diabetes and chronic lung diseases, such as asthma and chronic obstructive pulmonary disease, are on the increase and it is therefore of importance to study possible interactions between these conditions. In addition, an improved understanding of the natural history of diabetic lung function is needed in an era when pulmonary delivery of insulin is actively being pursued as a treatment option $[25,26]$. In the near future this treatment modality is likely to become a realistic option [27]. In this context, the reduced lung function in diabetics may have implications for the efficacy and safety of systemic insulin delivery via inhalation. Thus, an accurate description of the natural history of lung function in diabetes is needed, especially in type-2 disease (noninsulin-dependent diabetes mellitus), where inhaled insulin is likely to find its major use.

Previous cross-sectional analyses based on the results from The Copenhagen City Heart Study, have suggested that individuals with diabetes mellitus
(DM) have a slightly impaired forced vital capacity (FVC) and forced expiratory volume in one second (FEV1), compared with nondiabetic subjects [28]. This impairment was more pronounced in patients treated with insulin than in those with noninsulin-dependent DM. Longitudinal observations in the same cohort, based on a 5-yr observation period of 200 subjects with known DM, did not show a significantly steeper decline of ventilatory capacity in comparison with nondiabetic subjects [29]. However, the 126 participants who developed diabetes during a 5-yr observation period experienced a decline in both FVC and FEV1 that was almost twice as steep as nondiabetic subjects [29].

In the present study, results of longitudinal analyses of the decline of FVC and FEV1 in adults with mainly type-2 diabetes, based on a 15-yr follow-up of The Copenhagen City Heart Study, are presented.

\section{Methods}

The Copenhagen City Heart Study is a prospective epidemiological study initiated in 1976. Details on the selection procedure, the description of the nonresponders together with the complete examination 
programme for the two initial surveys have been presented previously [30]. Recently, a description of the third examination has been published [31].

Briefly, a sample comprising 19,698 individuals was drawn from the Copenhagen Population Register in January 1976, from a population of $\sim 90,000$ inhabitants aged $\geqslant 20$ yrs. The first examination round lasted 25 months from February 27 1976-March 31 1978. A total of 14,223 individuals were examined, i.e. $74 \%$ of those invited. In general, the response rates were highest among subjects $40-70$ yrs of age $(68-80 \%)$ and lowest among subjects aged $\geqslant 80$ yrs $(28-41 \%)$. The whole population sample (both responders and nonresponders), together with a new sample of 500 younger subjects aged 20-25 yrs, were invited for a second examination in 1981-1983, resulting in a total of 12,698 subjects being examined (response rate $70.2 \%$ ). Finally, a third examination of the cohort, together with an additional sample of 3,000 subjects aged 20-39 yrs was performed in 1991-1994. A total of 10,127 subjects participated in this examination (response rate 61.2\%). After exclusion of subjects with incomplete data, required for the longitudinal analyses of ventilatory function, the final sample consisted of 17,506 subjects; 8,136 males and 9,370 females, who attended at least one of the three examinations of the survey.

In the first and second examination of the survey, FEV1 and FVC were measured with an electronic spirometer (Monaghan N 403; Littleton, CO, USA), which was calibrated daily with a $1-\mathrm{L}$ syringe and weekly against a water-sealed Godard spirometer. In the third examination, a dry wedge spirometer (Vitalograph, Maidenhead, UK), which was calibrated weekly with a $1-\mathrm{L}$ syringe, was used. Unfortunately, at the time of the third survey the electronic spirometer used in the two previous examinations was no longer functioning, precluding a direct comparison between the two spirometers. Although differences in spirometers used over time can introduce a systematic bias, this bias is assumed to be of no importance with regard to longitudinal differences between diabetic and nondiabetic subjects, as it affects both groups in a similar manner. After at least one trial blow, three values were obtained. As a criterion of a correct performance, at least two measurements of FEV1 and FVC differing $<5 \%$ had to be produced. The best FEV1 and FVC were used in the analyses. Lung function data are reported in absolute values and as a percentage of predicted value (\% pred) according to internally derived prediction equations [32]:

$$
\mathrm{FEV}_{1}=410-27.6 \times \text { age }+21.2 \times \text { height }
$$

$$
\mathrm{FVC}=-217-28.4 \times \text { age }+28.1 \times \text { height }
$$

for females and by

$$
\begin{aligned}
& \mathrm{FEV}_{1}=-469-35.2 \times \text { age }+32.0 \times \text { height } \\
& \mathrm{FVC}=-1921-35.4 \times \text { age }+44.6 \times \text { height }
\end{aligned}
$$

for males, where height is in $\mathrm{cm}$.
Blood glucose was measured on a nonfasting venous blood sample using a hexokinase/glucose-6-phosphatedehydrogenase assay in plasma. A self-administered questionnaire concerning symptoms, somatic diseases, social status, smoking and drinking habits was filled out at each of the examination rounds and checked by one of the investigators. Chronic mucus hypersecretion $(\mathrm{CMH})$ was registered if the subjects were reported to bring up phlegm for at least 3 months a year for at least 2 yrs.

For the purpose of longitudinal analyses of the impact of diabetes on decline of ventilatory function, the subsample comprising 12,060 individuals with at least two measurements of pulmonary function was subdivided according to presence or absence of diabetes. In preliminary analyses, the authors differentiated between insulin-dependent diabetes mellitus (IDDM; defined as diabetes treated with insulin) and noninsulin-dependent diabetes mellitus (NIDDM), but since there were only 48 subjects with IDDM and as their lung function results were similar to those of the NIDDM group, these two groups were combined into a single "diabetes" group. This resulted in the following groupings: Normal: nondiabetic subjects throughout whole observation period, no self-reported diabetes and nonfasting blood glucose $<200 \mathrm{mg} \cdot \mathrm{dL}^{-1}$ $(<11.1 \mathrm{mM})$ at all examinations; Diabetes: subjects already with self-reported diabetes at the first examination (regardless of treatment) or subjects who at first examination already had a nonfasting blood glucose $\geqslant 200 \mathrm{mg} \cdot \mathrm{dL}^{-1}$; New diabetes mellitus (NewDM): no self-reported diabetes at the initial examination, but self-reported diabetes or a nonfasting blood glucose $\geqslant 200 \mathrm{mg} \cdot \mathrm{dL}^{-1}$ on at least one subsequent examination.

\section{Statistical analyses}

All analyses were performed for males and females separately. Since the unadjusted decline of lung function is difficult to interpret, a linear regression analysis of $\triangle \mathrm{FEV} 1$ and $\triangle \mathrm{FVC}$ for the participants with at least two valid measurements of lung function was performed. For each participant the longest observation period in days was defined, and the observed lung function decline normalised, so it could be expressed in $\mathrm{mL} \cdot \mathrm{yr}^{-1}$. The average observation period was 4,190 days $(\sim 11.5 \mathrm{yrs})$. This normalised decline was considered as $\mathrm{Y}$ and covariates measured at first examination were denoted as $\mathrm{X}=\left(\mathrm{X}_{1}, \ldots, \mathrm{X}_{\mathrm{m}}\right)$. The effect of the covariates on the response measure was assessed by regressing $\mathrm{Y}$ on $\mathrm{X}$ using the following model:

$$
\mathrm{Y}=\alpha+\beta_{1} \times \mathrm{X}_{1}+\ldots+\beta_{\mathrm{m}} \times \mathrm{X}_{\mathrm{m}}+\varepsilon
$$

assuming $\varepsilon$ to be normally distributed with mean 0 and unknown variance $\sigma^{2}$. The three diabetes groups were the independent variables of interest and the following potential confounding variables were included as covariates: age (yrs), smoking (no, yes), body mass index $\left(\mathrm{BMI} ; \mathrm{kg} \cdot \mathrm{m}^{-2} ;<18.5, \geqslant 18.5\right.$ and $<25, \geqslant 25$ and $<30, \geqslant 30$ and $<35, \geqslant 35$ ), $\mathrm{CMH}$ (no, yes), asthma (no, yes), previous myocardial infarction 
(no, yes), height $(\mathrm{m})$ and education $(\leqslant 7 \mathrm{yrs},>7$ and $<10 \mathrm{yrs}, \geqslant 10 \mathrm{yrs}$ ). Only the variables which are known determinants of lung function and were significant at the $5 \%$ level in the initial models were included in the final model. Interactions between various variables were investigated.

Taking advantage of the fact that many of the participants had three measurements of ventilatory function over time, a more detailed and accurate description of the age-specific ventilatory function was also performed by applying more advanced statistical modelling. As the response variable, the heightadjusted measurement of ventilatory function was defined either as $\mathrm{FEV} 1 /$ height $^{2}$ or $\mathrm{FVC}_{\text {height }}{ }^{2}$. As information on the exact time of onset of diabetes was unavailable, this analysis was restricted to subjects without diabetes (normal) and those with diabetes throughout the observation period (diabetes), and was carried out using specific methodology for covariatedependent random effects [33]. A nonlinear mixedeffects model with fixed effects depending upon age, smoking status, asthma, mucus hypersecretion and diabetes, and random effects depending upon diabetes only, was developed to utilise FVC and FEV1 measurements of all subjects who attended at least one examination [34]. Denoting the measurement, $j$, of height-adjusted ventilatory function $(j=1,2,3)$ on subject, $i$, with $Y_{i j}$ and covariates measured at the same examination (diabetes groups, smoking status, asthma, mucus hypersecretion) with $\mathrm{X}_{\mathrm{ij}}$, the data was modelled as:

$$
\mathrm{Y}_{\mathrm{ij}}=f\left(\alpha, \mathrm{age}_{\mathrm{ij}}\right)+\beta, \mathrm{X}_{\mathrm{ij}}+\eta * v_{\mathrm{i}}+\sigma * \varepsilon_{\mathrm{ij}}
$$

where $f$ is a general spline function with parameters $\alpha$ potentially different for each level of diabetes groups, $\beta$ the regression parameters of smoking status, asthma and mucus hypersecretion. The term $\eta * v_{\mathrm{i}}$ is a variance component depending on diabetes only with $v_{i}$ being an independent standard for normally distributed variables. This part models the dependence between subject-specific measurements of ventilatory function. The last term, $\sigma * \varepsilon_{\mathrm{ij}}$ is a normally distributed measurement error with potentially different sizes for diabetics and nondiabetics. The model was estimated using a restricted maximum likelihood method.

\section{Results}

The general characteristics of the subjects at the initial examination according to diabetes status, sex, age, BMI, smoking and length of school education are shown in table 1. Diabetic individuals were on average slightly older, had a higher average BMI and a shorter school education. In both sexes, nondiabetic individuals had a higher level of both FEV1 and FVC \% pred values, whereas those with diabetes had the lowest values. For the latter group, the reduction in both FEV1 and FVC was substantial, ranging $~ 8 \%$ of that predicted (table 1). Those who developed diabetes during the follow-up had an initial lung function level that was inbetween the other two groups.

Table 2 shows the unadjusted decline in lung function in $\mathrm{mL} \cdot \mathrm{yr}^{-1}$ according to the three diabetes groups and sex. As expected, the decline of both FEV1 and FVC measured in $\mathrm{mL} \cdot \mathrm{yr}^{-1}$ was higher in males than in females. With regard to lung function decline and DM grouping, there was no clear pattern, but in general the results did not suggest a faster decline among the diabetic individuals.

The results of the multiple linear regression analyses of FEV1 and FVC decline in females and males are shown in tables 3 and 4 . With regard to diabetes, no significant association between FEV1 and FVC decline and diabetes category was observed. Advanced age, smoking, asthma, CMH (only in males) and low BMI (only with regard to FEV1 decline) were significantly associated with increased decline of lung function.

The graphical description of the natural history of age-specific and height-adjusted FEV1 and FVC for participants with and without diabetes (groups: normal and diabetes) is shown in figures 1 and 2 . The curves of diabetic subjects differed significantly from

Table 1.-General characteristics of the participants at the enrolment into the study according to diabetes and sex

\begin{tabular}{|c|c|c|c|c|c|c|}
\hline & \multicolumn{3}{|c|}{ Females } & \multicolumn{3}{|c|}{ Males } \\
\hline & Normal & Diabetes & NewDM & Normal & Diabetes & NewDM \\
\hline Subjects $n$ & 6454 & 93 & 174 & 4891 & 173 & 277 \\
\hline Age yrs & $50.9(0.15)$ & $55.7(1.10)$ & $54.7(0.67)$ & $50.4(0.18)$ & $57.0(0.69)$ & $51.8(0.60)$ \\
\hline $\mathrm{BMI} \mathrm{kg} \cdot \mathrm{m}^{-2}$ & $24.3(0.05)$ & $28.3(0.70)$ & $29.5(0.41)$ & $25.5(0.05)$ & $27.3(0.36)$ & $28.8(0.24)$ \\
\hline Smoking $\%$ & 57.3 & 53.8 & 51.8 & 68.4 & 64.2 & 66.1 \\
\hline \multicolumn{7}{|l|}{ Education \% } \\
\hline$\leqslant 7$ yrs & 45.3 & 68.8 & 54.0 & 43.2 & 53.8 & 51.6 \\
\hline $7-10$ yrs & 24.2 & 15.1 & 24.2 & 24.0 & 24.9 & 23.1 \\
\hline$\geqslant 10 \mathrm{yrs}$ & 30.5 & 16.1 & 21.8 & 32.8 & 21.3 & 25.3 \\
\hline Asthma \% & 6.5 & 10.3 & 13.9 & 6.2 & 6.6 & 9.5 \\
\hline $\mathrm{CMH} \%$ & 9.0 & 13.0 & 12.1 & 12.3 & 15.0 & 15.2 \\
\hline FEV1 \% pred & $94.1(0.24)$ & $86.9(1.94)$ & $89.0(1.45)$ & $94.6(0.28)$ & $86.1(1.63)$ & 90.6 (1.19) \\
\hline FVC $\%$ pred & $97.4(0.21)$ & $90.5(1.72)$ & $91.3(1.25)$ & $97.1(0.25)$ & $89.8(1.41)$ & $92.6(1.04)$ \\
\hline
\end{tabular}

Data are presented as mean at first examination (SEM). DM: diabetes mellitus; BMI: body mass index; CMH: chronic mucus hypersecretion; FEV1: forced expiratory volume in one second; FVC: forced vital capacity. 
Table 2. - Unadjusted decline of forced expiratory volume in one second (FEV1) and forced vital capacity (FVC) according to diabetes and sex in the participants with at least two measurements of lung function

\begin{tabular}{|c|c|c|c|c|c|c|}
\hline & \multicolumn{3}{|c|}{ Females } & \multicolumn{3}{|c|}{ Males } \\
\hline & Normal & Diabetes & NewDM & Normal & Diabetes & NewDM \\
\hline Subjects $n$ & 6454 & 93 & 174 & 4891 & 173 & 277 \\
\hline$\Delta \mathrm{FEV}_{1 \mathrm{~mL}} \cdot \mathrm{yr}^{-1}$ & $24.0(0.69)$ & $23.9(7.24)$ & $26.1(2.96)$ & $33.6(1.05)$ & $28.2(7.69)$ & $36.4(3.39)$ \\
\hline$\Delta \mathrm{FVC} \mathrm{mL} \cdot \mathrm{yr}^{-1}$ & $23.0(0.79)$ & $24.3(8.83)$ & $23.3(3.87)$ & $30.3(1.25)$ & $39.6(7.53)$ & $35.2(4.19)$ \\
\hline
\end{tabular}

Mean values for an average observation of $\sim 11.5$ yrs (SEM). DM: diabetes mellitus.

the curves of nondiabetic individuals $(\mathrm{p}<0.001)$, but this was due to the lower level values among diabetic individuals, whereas the decline itself did not differ significantly.

\section{Discussion}

Similarly to other investigators, FVC and FEV1 were found to be consistently and significantly lower in diabetic individuals compared with normal subjects [1-24]. On average, the difference was quite substantial and $\sim 8 \%$ pred, which is comparable to an average difference between a smoker and a never-smoker. As in some previous studies, individuals who developed diabetes later were observed to have a lower level of lung function initially [35-37].

The main focus of the analyses was the decline of lung function. This was investigated using both a conventional linear regression and by employing advanced modelling, which took advantage of three measurements in many of the participants and corrected for repeated measurements in a single individual. Both methods showed that the decline of lung function was not faster in diabetic individuals compared with normal subjects. With regard to the impact of confounders, like smoking and asthma, included in the longitudinal analyses of lung function decline, the present results are consistent with previous findings [38-40]. High BMI is known to relate to both high incidence of diabetes and to a reduced ventilatory capacity. In the longitudinal analyses, low BMI was significantly related to accelerated decline of FEV1. There was, however, no significant interaction between diabetes and BMI on FEV1 decline, suggesting similar effects of BMI in diabetic and nondiabetic participants.

The present results from the 15-yr follow-up are in keeping with the previous report from the cohort based on 5 yrs of observation, and with the only other true longitudinal study which was performed on diabetic children [8, 29]. The figures describing the course of FEV1 and FVC show that although the level of lung function is already consistently lower at $30 \mathrm{yrs}$

Table 3. - Multiple linear regression of change in forced expiratory volume in one second $\left(\mathrm{mL}^{-} \mathrm{yr}^{-1}\right)$ based on an average observation period of $11.5 \mathrm{yrs}$ of the participants with at least two measurements of lung function

\begin{tabular}{|c|c|c|c|c|c|c|}
\hline \multirow[t]{2}{*}{ Variable } & \multicolumn{3}{|c|}{ Females } & \multicolumn{3}{|c|}{ Males } \\
\hline & Estimate & SEM & p-value & Estimate & SEM & p-value \\
\hline Intercept & 69.01 & 8.76 & $<0.0001$ & 75.8 & 13.0 & $<0.0001$ \\
\hline Age & -2.54 & 0.37 & $<0.0001$ & -3.40 & 0.55 & $<0.0001$ \\
\hline $\mathrm{Age}^{2}$ & 0.015 & 0.0037 & $<0.0001$ & 0.02 & 0.0056 & $<0.0001$ \\
\hline Smoking & & & $<0.0001$ & & & $<0.0001$ \\
\hline No & 0 & & & 0 & & \\
\hline Yes & -9.21 & 1.35 & & -12.2 & 2.21 & \\
\hline BMI & & & 0.0008 & & & 0.01 \\
\hline $\begin{array}{l}<18.5 \\
\geqslant 18.5 \text { and }<25\end{array}$ & -3.63 & 3.98 & & $\begin{array}{c}-11.3 \\
0\end{array}$ & 11.7 & \\
\hline $\begin{array}{l}\geqslant 18.5 \text { and }<25 \\
\geqslant 25 \text { and }<30\end{array}$ & $\begin{array}{l}0 \\
2.09\end{array}$ & 1.55 & & 7.37 & 2.22 & \\
\hline$\geqslant 30$ and $<35$ & 10.2 & 2.61 & & 4.02 & 3.78 & \\
\hline$\geqslant 35$ & 7.97 & 4.12 & & 9.03 & 8.13 & \\
\hline $\mathrm{CMH}$ & & & 0.18 & & & 0.006 \\
\hline No & 0 & & & 0 & & \\
\hline Yes & -3.20 & 2.41 & & -9.03 & 3.28 & \\
\hline Asthma & & & 0.006 & & & 0.006 \\
\hline No & 0 & & & 0 & & \\
\hline Yes & -7.33 & 2.68 & & -11.57 & 4.20 & \\
\hline Diabetes & & & 0.97 & & & 0.33 \\
\hline Normal & 0 & & & 0 & & \\
\hline Diabetes & 0.65 & 5.79 & & 7.91 & 5.82 & \\
\hline NewDM & -0.88 & 4.27 & & -2.46 & 4.67 & \\
\hline
\end{tabular}

BMI: body mass index; CMH: chronic mucus hypersecretion; DM: diabetes mellitus. 
Table 4. - Multiple linear regression of change in forced vital capacity $\left(\mathrm{mL} \cdot \mathrm{yr} \mathrm{r}^{-1}\right)$ based on an average observation period of $11.5 \mathrm{yrs}$ of the participants with at least two measurements of lung function

\begin{tabular}{|c|c|c|c|c|c|c|}
\hline \multirow[t]{2}{*}{ Variable } & \multicolumn{3}{|c|}{ Females } & \multicolumn{3}{|c|}{ Males } \\
\hline & Estimate & SEM & p-value & Estimate & SEM & p-value \\
\hline Intercept & 90.7 & 10.1 & $<0.0001$ & 90.7 & 15.2 & $<0.0001$ \\
\hline Age & -3.17 & 0.43 & $<0.0001$ & -3.52 & 0.65 & $<0.0001$ \\
\hline $\mathrm{Age}^{2}$ & 0.02 & 0.0043 & $<0.0001$ & 0.024 & 0.0065 & 0.0003 \\
\hline Smoking & & & $<0.0001$ & & & $<0.0001$ \\
\hline No & 0 & & & 0 & & \\
\hline Yes & -6.12 & 1.57 & & -11.0 & 2.60 & \\
\hline BMI & & & 0.28 & & & 0.89 \\
\hline $\begin{array}{l}<18.5 \\
\geq 18.5 \text { and }<25\end{array}$ & -1.61 & 4.61 & & -0.62 & 13.7 & \\
\hline$\geqslant 18.5$ and $<25$ & 0 & & & 0 & & \\
\hline$\geqslant 25$ and $<30$ & -0.073 & 1.80 & & 2.18 & 2.61 & \\
\hline$\geqslant 30$ and $<35$ & 6.27 & 3.02 & & 3.84 & 4.45 & \\
\hline$\geqslant 35$ & 3.38 & 4.78 & & 2.09 & 9.55 & \\
\hline $\mathrm{CMH}$ & & & 0.11 & & & 0.01 \\
\hline No & 0 & & & 0 & & \\
\hline Yes & -4.44 & 2.79 & & -9.52 & 3.86 & \\
\hline Asthma & & & 0.04 & & & 0.12 \\
\hline No & 0 & & & 0 & & \\
\hline Yes & -6.40 & 3.11 & & -7.67 & 4.94 & \\
\hline Diabetes & & & 0.65 & & & 0.85 \\
\hline Normal & 0 & & & 0 & & \\
\hline Diabetes & 1.73 & 6.70 & & -1.06 & 6.87 & \\
\hline NewDM & 4.47 & 4.94 & & -3.06 & 5.49 & \\
\hline
\end{tabular}

BMI: body mass index; CMH: chronic mucus hypersecretion; DM: diabetes mellitus.

of age, the difference between diabetic and nondiabetic subjects does not increase with age.

Individuals who developed diabetes during the followup were included in the linear regression as the NewDM group, but contrary to previous finding based on the 5 -yr follow-up, their decline of lung function was not

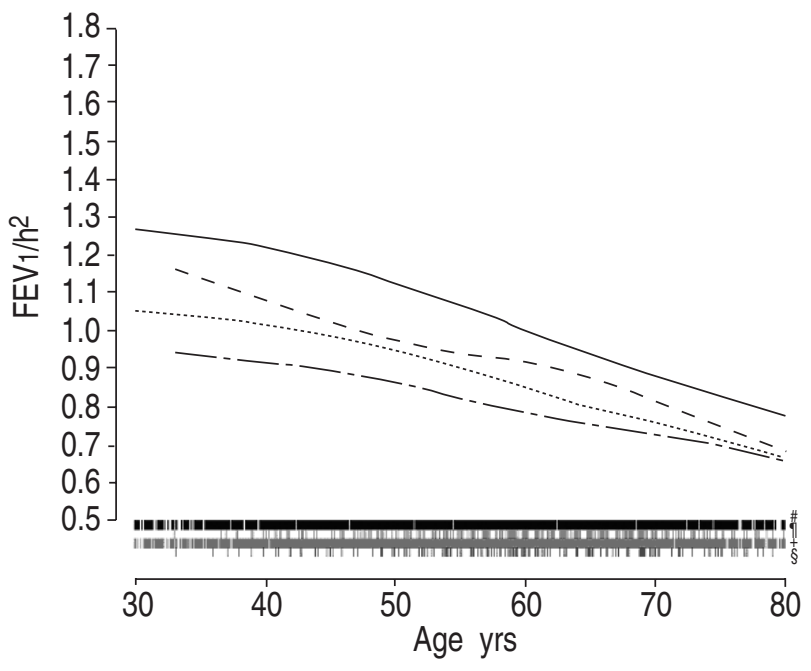

Fig. 1.-Age-specific height (h)-adjusted forced expiratory volume in one second $(\mathrm{FEV} 1)$ for male $(---)$ and female $(-\cdot-)$ diabetic, and male $(-)$ and female $(\cdots \cdots)$ nondiabetic individuals when accounting for smoking, asthma and mucus hypersecretion. Based on a mixed-effects model taking into account the correlation between serial measurements in individual participants. Lines below represent number of measurements on which each curve is based. ": male normals; ": male diabetes mellitus; ${ }^{+}$: female normals; $§$ : female diabetes mellitus. accelerated during the $\sim 11.5$ yrs of follow-up [29]. However, the authors cannot entirely reject the hypothesis that newly developed diabetes could be associated with a faster decline of lung function. This possibility could have been overlooked, as the present study design had quite long intervals between the single measurements

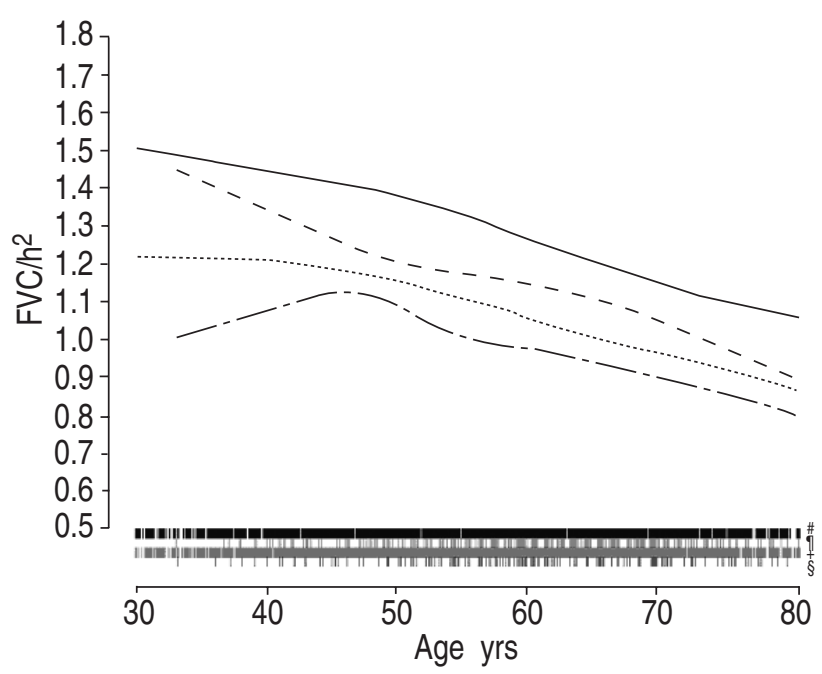

Fig. 2.-Age-specific height (h)-adjusted forced vital capacity (FVC) for male (- - ) and female $(-\cdot-)$ diabetic, and male $(-)$ and female (.....) nondiabetic individuals when accounting for smoking, asthma and mucus hypersecretion. Based on a mixedeffects model taking into account the correlation between serial measurements in individual participants. Lines below represent number of measurements on which each curve is based. \#: male normals; ${ }^{\circ}$ : male diabetes mellitus; ${ }^{+}$: female normals; ${ }^{\S}$ : female diabetes mellitus. 
of lung function ( 5 and $10 \mathrm{yrs}$ ), and also lacked information regarding the precise onset of diabetes. These limitations are also the reason for not including the NewDM group in the advanced statistical model.

Although the present study is among the largest studies of lung function in diabetes and has the longest observation period, it has also some limitations, the most important being the definition of diabetes. In the present study, this is either based on self-reporting, which is very likely to underestimate the prevalence, or a single measurement of a nonfasting blood glucose value $\geqslant 200 \mathrm{mg} \cdot \mathrm{mL}^{-1}$. The authors gained no information on fasting blood glucose, oral glucose tolerance test, nor diabetic symptoms like polyuria or polydypsia. They are aware that the true prevalence and incidence of diabetes in this cohort was underestimated, and that the underdiagnosis of DM was higher in the first survey in 1976-1978 than in the following surveys in 1981-1983 and 1991-1994, due to an increase in general public awareness of diabetes.

With regard to diabetes treatment, the database only comprised information relating to whether the individuals were on a diet, oral hypoglycaemic agents and/or insulin. Based on these data, the vast majority of the diabetic participants were assumed to have type-2 diabetes, which in previous studies has been associated with slightly smaller pulmonary abnormalities than type-1 diabetes [1-24]. Exclusion of patients on insulin from the lung function analyses did not change the results and therefore it was decided that those individuals would be kept in the final analyses. Although the underdiagnosis of diabetes may have an affect on the conclusions, with regard to lung function decline, this seems unlikely as undiagnosed diabetics are likely to have milder diabetes and thus also a smaller lung function deficit compared with nondiabetics.

In general, an observation period of $3-5 \mathrm{yrs}$ is considered necessary in order to determine the rate of lung function decline [41]. With regard to comparison of these results with future studies of lung function changes in diabetics treated with pulmonary insulin, it should be remembered that it is difficult to compare absolute declines of FEV1 and FVC in $\mathrm{mL} \cdot \mathrm{yr}^{-1}$ between studies. In particular, between an epidemiological study, like this one, with long intervals between single measurements and a clinical trial with fewer participants but with more frequent measurements of lung function. Therefore, although this epidemiological study based on a long observation period does not support the notion that diabetics, as a group, have a faster decline in lung function than nondiabetics, this could still be the case for single individuals, especially those with severe type- 1 diabetes.

It has been suggested that the inflammatory response may be altered in diabetes and that this could lead to increased inflammatory responses in the lung, resulting in lung function impairment [35]. Some previous studies have reported more pronounced pulmonary deficits in diabetics with long-term complications like nephropathy [10], retinopathy [20], neuropathy [17] and limited joint mobility [21]. Yet, the results have been inconsistent and the mechanism responsible for the association between reduced lung function and diabetes is at present unknown. The fact that pulmonary deficits do not seem to increase with age (and thus with the duration of diabetes) does not suggest that lung function reduction should be regarded as a long-term complication of diabetes. In line with this notion, it has been suggested that some pre-existing factors, for example low birth weight, could be the link between both type-2 diabetes [42] and low lung function in adulthood [43]. Such a mechanism, although highly speculative, is consistent with the observation that lung function is already reduced before the clinical manifestation of diabetes (table 1).

Although the level of forced expiratory volume in one second and forced vital capacity is lower in diabetes, the decline of lung function is similar to that observed in nondiabetic subjects. The implication of these findings for the surveillance of diabetic patients on inhaled insulin is two-fold. On one hand, the fact that the lung function deficit in diabetes does not seem to progress with increasing age and duration of the disease is reassuring for elderly patients, who in the future can also be offered treatment with pulmonary insulin. On the other hand, if the patient on inhaled insulin experiences an increased lung function decline, this is not likely to be caused by diabetes itself but should rather be considered as a result of another lung disease or as a possible side-effect of the pulmonary insulin.

\section{References}

1. Cooper BG, Taylor R, Alberti KG, Gibson GJ. Lung function in patients with diabetes mellitus. Respir Med 1990; 84: 235-239.

2. Heimer D, Brami J, Liberman D, Bark H. Respiratory muscle performance in patients with type 1 diabetes. Diabetic Med 1990; 7: 434 437.

3. Britton J. Is the carbon monoxide transfer factor diminished in the presence of diabetic retinopathy in patients with insulin-dependent diabetes mellitus. Eur Respir J 1988; 1: 403-406.

4. Bell D, Collier A, Matthews D, Cooksey E, Medhardy $\mathrm{G}$, Clarke B. Are reduced lung volumes in IDDM due to a defect in connective tissue? Diabetes 1988; 37: 829-831.

5. Sandler M, Bunn AE, Stewart RI. Cross-section study of pulmonary function in patient with insulin-dependent diabetes mellitus. Am Rev Respir Dis 1987; 135: 223-229.

6. Strojek K, Ziora D, Sroczynski JW, Oklek K. Pulmonary complications of type 1 diabetic patients. Diabetologia 1992; 35: 1173-1176.

7. Innocenti F, Fabbri A, Anichini $\mathrm{R}$, et al. Indications of reduced pulmonary function in type 1 diabetes mellitus. Diabetes Res Clin Pract 1994; 25: 161-168.

8. Primhak R, Whincup G, Tsanakas J, Milner R. Reduced vital capacity in insulin-dependent diabetes. Diabetes 1987; 36: 324-326.

9. Sandler M, Bunn A, Stewart R. Pulmonary function in young insulin-dependent diabetic subjects. Chest 1986; 90: 670-675.

10. Schnack CH, Festa A, Schwarzmaier-Dássie A, Haber P, Schernthaner G. Pulmonary dysfunction in type 1 diabetes in relation to metabolic long-term control 
and incipient diabetic nephropathy. Nephron 1996; 74 : 395-400.

11. Minette P, Buysschaert M, Rahier J, Veriter C, Frans A. Pulmonary gas exchange in life-long non-smoking patients with diabetes mellitus. Respiration 1999; 66: 20-24.

12. Schnopf BM, Banks R, Silverstein J, Rosenbloom A, Chesrown S, Loughlin G. Pulmonary function in insulin-dependent diabetes mellitus with limited joint mobility. Am Rev Respir Dis 1984; 130: 930-932.

13. Ramirez L, Dal Nogare A, Hsia C, et al. Relationship between diabetes control and pulmonary function in insulin-dependent diabetes mellitus. Am J Med 1991; 91: 371-376.

14. Niranjan V, McBrayer DG, Ramirez LC, Raskin P, Hsia CC. Glycemic control and cardiopulmonary function in patients with insulin-dependent diabetes mellitus. Am J Med 1997; 103: 504-513.

15. Wanke T, Paternostro-Sluga T, Grisold W, et al. Phrenic nerve function in type 1 diabetic patients with diaphragm weakness and peripheral neuropathy. Respiration 1992; 59: 23-37.

16. Schernthaner G, Haber P, Kummer F, Ludwig H. Lung elasticity in juvenile-onset diabetes mellitus. $A m$ Rev Respir Dis 1977; 116: 544-546.

17. Tantucci C, Scionti L, Bottini P, et al. Influence of autonomic neuropathy of different severities on the hypercapnic drive to breathing in diabetic patients. Chest 1997; 112: 145-153.

18. Santos e Fonseca CM, Manco JC, Gallo Junior L, Barreira AA, Foss MC. Cholinergic bronchomotor tone and airway caliber in insulin-dependent diabetes mellitus. Chest 1992; 101: 1038-1043.

19. Mori H, Okubo M, Okamura M, et al. Abnormalities of pulmonary function in patients with non-insulindependent diabetes mellitus. Intern Med 1992; 31: 189 193.

20. Isotani H, Nakamura Y, Kameoka K, et al. Pulmonary diffusing capacity, serum angiotensin-converting enzyme activity and the angotensin converting enzyme gene in Japanese non-insulin-dependent diabetes mellitus patients. Diabetes Res Clin Pract 1999; 43: 173-177.

21. Barret-Connor E, Frette C. NIDDM, impaired glucose tolerance, and pulmonary function in older adults: The Rancho Bernardo Study. Diabetes Care 1996; 19: 1441-1444

22. Marvisi M, Bartolini L, del Borello P, et al. Pulmonary function in non-insulin-dependent diabetes mellitus. Respiration 2001; 68: 268-272.

23. Davis TM, Knuiman M, Kendall P, Vu H, Davis WA. Reduced pulmonary function and its association in type 2 diabetes: The Fremantle Diabetes Study. Diabetes Res Clin Pract 2000; 50: 153-159.

24. Katoh J, Hara Y, Kurusu M, Miyaji J, Narutaki K. Cardiorespiratory function as assessed by exercise testing in patients with non-insulin dependent diabetes mellitus. J Int Med Res 1996; 24: 209-213.

25. Skyler JS, Cefalu WT, Kourides IA, et al. Efficacy of inhaled human insulin in type 1 diabetes mellitus: A randomised proof-of-concept study. Lancet 2001; 357: 331-335.

26. Cefalu WT, Skyler JS, Kourides IA, et al. Inhaled insulin study group. Report of short-term efficacy and safety of inhaled insulin in adults with type 2 diabetes mellitus. Ann Intern Med 2001; 134: 203-207.

27. Cefalu WT. Novel routes of insulin delivery for patients with type 1 or type 2 diabetes. Ann Med 2001; 33: 579-586.

28. Lange P, Groth S, Kastrup J, et al. Diabetes mellitus, plasma glucose and lung function in a cross-sectional population study. Eur Respir J 1989; 2: 14-19.

29. Lange $\mathrm{P}$, Groth S, Mortensen J, et al. Diabetes mellitus and ventilatory capacity. A five-year followup. Eur Respir J 1990; 3: 288-292.

30. Appleyard M. The Copenhagen City Heart Study: Osterbroundersøgelsen: a book of tables with the data from the first examination (1976-1978) and a five-year follow-up (1981-1983). Scand J Soc Med 1989; 41: 1160.

31. Schnohr $P$, Jensen $G$, Lange $P$, Scharling $H$, Appleyard M. The Copenhagen City Heart Study. Tables with data from the third examination 1991-1994. Eur Heart J 2001; 3: Suppl. H, 1-83.

32. Lange P, Nyboe J, Jensen G, Schnohr P, Appleyard M. Ventilatory function impairment and risk of cardiovascular death and of fatal or non-fatal myocardial infarction. Eur Respir J 1991; 4: 10801087.

33. Laird NM, Ware JH. Random-effects models for longitudinal data. Biometrics 1982; 38: 963-974.

34. Vonesh EF, Carter RL. Mixed-effects nonlinear regression for unbalanced repeated measures. Biometrics 1992; 48: 1-17.

35. Engström G, Janzon L. Risk of developing diabetes is inversely related to lung function: a population-based cohort study. Diabetic Med 2002; 19: 167-170.

36. Lazarus R, Sparrow D, Weiss ST. Baseline ventilatory function predicts the development of higher levels of fasting insulin resistance index: The Normative Ageing Study. Eur Respir J 1998; 12: 641-645.

37. Eriksson KF, Lindgärde F. Poor physical fitness, and impaired early insulin response but late hyperinsulinaemia, as predictors of NIDDM in middle-aged Swedish men. Diabetologia 1996; 39: S73-S79.

38. Lange P, Groth S, Mortensen J, et al. The effects of smoking and changes in smoking habits on decline of FEV1. Eur Respir J 1989; 2: 811-816.

39. Lange P, Parner J, Vestbo J, Jensen G, Schnohr P. A 15-yr follow-up of ventilatory function in adults with asthma. N Engl J Med 1998; 339: 1194-1200.

40. Vestbo J, Prescott E, Lange P, and The Copenhagen City Heart Study Group. Association of chronic mucus hypersecretion with FEV1 decline and chronic obstructive disease mortality. Am J Respir Crit Care Med 1996; 153: 1530-1535.

41. Burrows B, Lebowitz MD, Camilli AE, Knudson RJ. Longitudinal changes in FEV1 in adults: methodologic considerations and findings in healthy nonsmokers. Am Rev Respir Dis 1986; 133: 974-980.

42. Lithell HO, McKeigue PM, Berglund L, Mohsen R, Lithell UB, Leon DA. Relation of size at birth to noninsulin dependent diabetes and insulin concentrations in men aged 50-60. BMJ 1996; 312: 406-410.

43. Barker DJ, Gedfrey KM, Fall C, Osmond C, Winter $\mathrm{PD}$, Shaheen SO. Relation of birth weight and childhood respiratory infection to adult lung function and death from chronic obstructive lung disease. $B M J$ 1991; 303: 671-675. 